\title{
Tingkat Keamanan Nasi Campur Yang Dijual Di Lingkungan Pasar Badung Ditinjau Dari Aspek Mikrobiologi
}

\author{
Yulianus Jordi Ziku, Ni Made Ayu Suardani Singapurwa, I Wayan Sudiarta \\ Program Studi Ilmu dan Teknologi Pangan, Fakultas Pertanian, Universitas Warmadewa \\ E-mail: jordijidor@gmail.com
}

\begin{abstract}
Production activities each company are expecting the creation of productivity. This research was aims to determine levels of total and partial productivity by using Objective Matrix and propose improvements. The study was conducted at Perkebunan Kandangan Pulosari Panggungsari plantations began from January to April 2015. The data gathered consist of secondary data and primary data. Elements analyzed the productivity of human, machine, wood fuel and diesel fuel.

The results showed that the value of productivity was experiencing fluctuating, the value of total productivity in the processing of coffee by 6.660. Partial productivity value on the human element of 1.635, 1.463 for labor, fuelwood amounted to 1,162, working hours standing to 0.894 generator engines and diesel fuel of 1.49. Proposed improvements that can be done by optimizing the number and performance of every element of productivity.
\end{abstract}

\section{Keywords: Coffee, Improvements, Objective Matrix, Productivity.}

\section{Pendahuluan}

Makanan merupakan sumber energi dan gizi bagi manusia untuk melaksanakan aktivitasnya seharihari. Tanpa makanan, manusia tidak memiliki tenaga untuk bisa melaksanakan berbagai rutinitasnya setiap hari. (Departemen Kesehatan RI, 2004). Makanan yang sehat dan aman merupakan salah satu faktor yang penting untuk meningkatkan derajat kesehatan, oleh karena itu kualitas makanan yang baik secara bakteriologis, kimiawi, maupun fisik harus selalu dipertahankan. Oleh karena itu higiene dan sanitasi pengolahan makanan perlu mendapatkan perhatian yang lebih seksama. (Singapurwa et al., 2017).

Higiene dan sanitasi merupakan hal yang penting dalam menentukan kualitas makanan dimana Escherichia coli sebagai salah satu indikator terjadinya pencemaran makanan yang dapat menyebabkan penyakit akibat makanan (food borne diseases). Bakteri-bakteri indikator pada umumnya adalah bakteri lazim terdapat dan hidup sebagai flora normal pada usus manusia. Bakteri E.coli dapat menimbulkan gangguan kesehatan seperti penyakit diare apabila masuk ke saluran pencernaan, baik melalui minuman maupun makanan. Peraturan Menteri Kesehatan RI nomor 1098/Menkes/SK/VII/2003 angka kuman E.coli pada makanan harus 0/gram sampel makanan dan pada minuman angka kuman E.coli harus 0/100 ml sampel minuman.

Makanan yang telah dicemari oleh bakteri setelah dikonsumsi biasanya menimbulkan gejala-gejala seperti muntah-muntah, demam, sakit perut, gejala terjadi 4-12 jam yang memberi kesan langsung pada lapisan usus dan menyebabkan peradangan. Ada berbagai jenis bakteri yang menyebabkan keracunan makanan, diantaranya Salmonella, Staphylococcus dan Escherechia coli yang merupakan faktor keracunan makanan. (BPOM, 2003). Kontaminasi E.coli makanan menurut jenis Tempat Pengelolaan Makanan (TPM) yaitu kontaminasi E.coli makanan restoran di hotel 33,3\%, rumah makan 31.3\%, jasa boga 38.2\%, warung 32.9\%, pedagang kaki lima 40.7\% dan industri makanan 21.3\%. (Djaja, 2006).

Salah satu tempat yang rentan terhadap pencemaran adalah pasar, termasuk makanan yang di jajahkan 
atau dijual dilingkungan pasar seperti halnya nasi campur. Berdasarkan hal tersebut, maka dilakukan penelitian menganalisis kontaminan bakteri E. Coli di pasar Badung, dimana lokasi dan keadaan pasar Badung sangat rentan untuk terkontaminasi oleh bakteri tersebut.

\section{Bahan dan Metoda}

Penelitian ini dilaksanakan di Laboratorium Balai Besar Veteriner Denpasar. Penelitian ini dilaksanakan pada tanggal 7 April 2016 sampai pada tanggal 4 Mei 2016. Pengambilan Sampel pada tanggal 7 April dan 25 April 2016. Bahan-bahan yang digunakan dalam penelitian ini adalah nasi campur, yaitu nasi campur yang diambil dari 6 pedagang di lingkungan sekitar Pasar Badung Bali, Plate Count Agar (PCA), BPW 0,1\% (Buffered Pepton Water 0,1\%), BGLBB (Brilliant Green Lactose Bile Broth), LSTB (Lauryl Sulfate Tryptose Broth), ECB (Escherichia Coli Broth), L-EMBA (Levine Eosin Methylene Blue Agar), MR-VP (Methyle Red-Voges Proskauer), KCB (Koser Citrate Broth), SCA (Simmons Citrate Agar), Reagen Kovas, Reagen Voges-Proskauer (VP).

Alat-alat yang digunakan dalam penelitian ini adalah : cawan petri, tabung reaksi, pipet volumetrik, botol media, penghitung koloni (Colony counter), gunting, pinset, jarum inokulasi (ose), stomacher, pembakar bunsen, $\mathrm{pH}$ meter, timbangan, magnetic stirer, pengocok tabung (vortex), inkubator, penangas air, autoklaf, lemari steril (clean bench), lemari pendingin (refrigerator), freezer, tabung Durham, pipet ukuran (1 ml, $2 \mathrm{ml}, 5 \mathrm{ml}, 10 \mathrm{ml})$.

Penelitian ini merupakan penelitian eksploratif yang menggunakan desain eksperimen di laboratorium. Jenis penelitian ini adalah Deskriptif Analitis. Populasinya adalah pedagang makanan nasi campur di lingkungan pasar Badung yaitu sebanyak enam pedagang. Teknik pengambilan sampelnya dari setiap pedagang diambil dua kali sampel makanan, yaitu pada pagi dan siang. Pengambilan data dilakukan dengan metode analisa sampel secara mikrobiologis yang meliputi analisa kontaminan mikroba E.coli dan analisa total mikroba di Laboratorium Balai Besar Veteriner Denpasar dan observasi di lingkungan pedagang.

Pengamatan mikrobiologi dilakukan dengan dua perlakuan, berupa waktu pengambilan sampel yang berbeda, yaitu : pengambilan sampel pagi (Pukul 08:00 WITA) dan pengambilan sampel siang (Pukul 14:00 WITA). Dari dua perlakuan tersebut masing-masing sampel diambil dan diulang sebanyak 2 (dua) kali ulangan, sehingga diperoleh 6 × 2 × $2=24$ sampel.

Penelitian ini dilakukan dengan pengambilan sampel dari 6 orang pedagang nasi campur dari jumlah 9 pedagang nasi campur di lingkungan Pasar Badung. Penelitian ini meliputi uji mikrobiologis yaitu analisis mikroba E.coli dan analisis total mikroba.

Analisa E.coli (SNI 2897:2008) dilakukan dengan pengambilan sampel dari pedagang nasi campur pada pagi hari pukul 08:00 WITA secara bersamaan, kemudian sampel tersebut di bawa ke Laboratorium Balai Besar Veteriner Denpasar untuk diuji dan dianalisis. Sampel kedua diambil pada pukul 14:00 WITA atau 6 jam setelah pengambilan sampel pertama untuk mengetahui atau menganalisis perkembangan dan pertumbuhan mikroba.

Pengujian MPN Escherichia coli dilakukan dengan Uji pendugaan, Uji konfirmasi (peneguhan), Interpretasi hasil, Isolasi-identifikasi, Uji biokimia dengan uji IMVi, Uji produksi Indole, Uji Methyl Red (MR) dan Uji Voges-Proskauer (VP). Analisa Total Mikroba dilakukan berdasarkan SNI 2897:2008. 


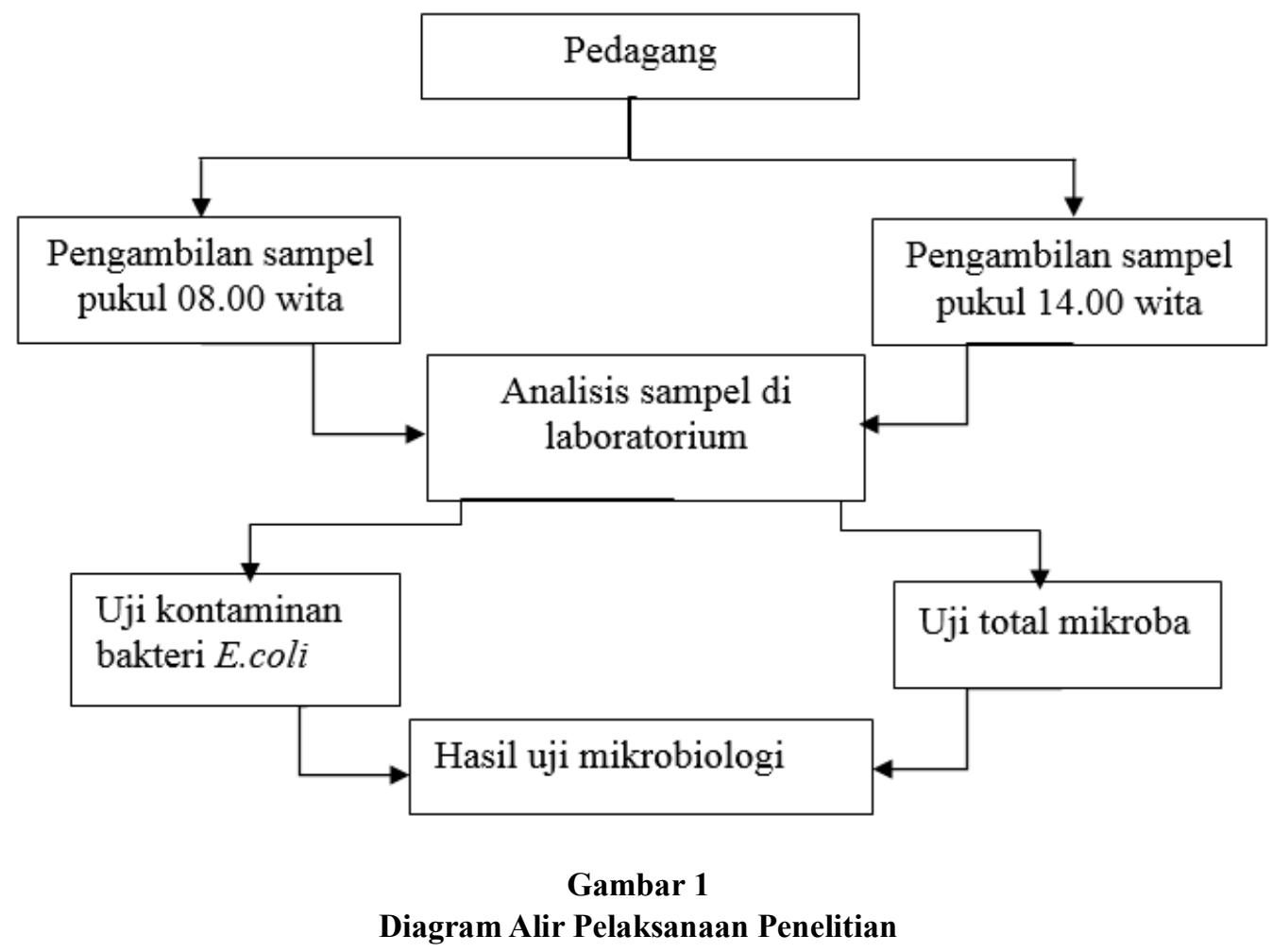

\section{Hasil dan Pembahasan}

\subsection{Analisa Kontaminan Bakteri Escherichia coli}

Sampel makanan yang akan di uji diambil dari 6 pedagang di lingkungan Pasar Badung Bali pada tanggal 7 April dan 25 April 2016. Sampel dari setiap pedagang diambil 2 kali dalam satu hari yaitu pada pagi (pukul 08:00 wita) dan siang hari (pukul 14:00 wita) sehingga jumlah sampel yang diuji adalah 24 sampel. Analisa kontaminan bakteri Escherichia coli dilakukan dengan menggunakan pengujian Most Probable Number (MPN). Pengujian ini dilakukan dengan uji pendugaan, uji peneguhan, dan isolasi-identifikasi melalui uji biokimia Indole, Methyl Red, Voges Proskauer dan Citrate (IMViC).

Pemeriksaan pertama sampel dilakukan dengan uji dugaan menggunakan Lauryl Sulfate Tryptose Broth (LSTB). Tabung yang mengandung bakteri coliform akan menunjukan adanya gas yang terperangkap pada tabung Durham. Tabung yang positif terdapat gas dilanjutkan dengan uji peneguhan menggunakan Escherichia coli Broth (ECB). Tabung yang positif pada uji peneguhan ditandai dengan adanya gas yang terperangkap pada tabung Durham dan kemudian dilakukan interpretasi dengan cara mencocokan hasil yang diperoleh dengan Tabel indeks Most Probable Number (MPN).

Hasil uji peneguhan terhadap 24 sampel yang diuji dapat dilihat pada Tabel.1. Pada Tabel 1 dapat dilihat bahwa semua sampel yang diuji menunjukan total nilai bakteri coliform $>3.6 \mathrm{MPN} / \mathrm{g}$. Menurut Standar Nasional Indonesia (SNI) 2897: 2008 standar Most Probable Number (MPN) cemaran bakteri coliform adalah <3.6 MPN/gr. Untuk mengetahui ada tidaknya bakteri Escherichia coli maka dilanjutkan dengan uji isolasi pada media Eosyn Methylene Blue Agar (EMBA) dan uji biokimia Indole, 
Methyl Red Voges Proskauer dan Citrate (IMViC). Isolasi pada media EMBA dilakukan terhadap masing -masing pengenceran yang menunjukan hasil positif pada uji peneguhan. Hasil isolasi pada media EMBA dapat dilihat pada Tabel 2.

Tabel 1.

Hasil Uji Peneguhan Terhadap 24 Sampel Nasi Campur di Lingkungan Pasar Badung.

\begin{tabular}{|c|c|c|c|c|c|}
\hline No. & Tanggal & Pedagang & Waktu pengambilan & Nilai MPN/g & Keterangan \\
\hline 1 & 7 April 2016 & 1 & Pagi (08:00 wita) & 240 & TMS \\
\hline 2 & 7 April 2016 & 2 & Pagi (08:00 wita) & 210 & TMS \\
\hline 3 & 7 April 2016 & 3 & Pagi (08:00 wita) & 3,6 & TMS \\
\hline 4 & 7 April 2016 & 4 & Pagi (08:00 wita) & 240 & TMS \\
\hline 5 & 7 April 2016 & 5 & Pagi (08:00 wita) & 1100 & TMS \\
\hline 6 & 7 April 2016 & 6 & Pagi (08:00 wita) & 150 & TMS \\
\hline 7 & 7 April 2016 & 1 & Siang (14:00 wita) & $>1100$ & TMS \\
\hline 8 & 7 April 2016 & 2 & Siang (14:00 wita) & $>1100$ & TMS \\
\hline 9 & 7 April 2016 & 3 & Siang (14:00 wita) & 150 & TMS \\
\hline 10 & 7 April 2016 & 4 & Siang (14:00 wita) & 75 & TMS \\
\hline 11 & 7 April 2016 & 5 & Siang (14:00 wita) & $>1100$ & TMS \\
\hline 12 & 7 April 2016 & 6 & Siang (14:00 wita) & $>1100$ & TMS \\
\hline 13 & 25 April 2016 & 1 & Pagi (08:00 wita) & 93 & TMS \\
\hline 14 & 25 April 2016 & 2 & Pagi (08:00 wita) & 460 & TMS \\
\hline 15 & 25 April 2016 & 3 & Pagi (08:00 wita) & 3,6 & TMS \\
\hline 16 & 25 April 2016 & 4 & Pagi (08:00 wita) & 240 & TMS \\
\hline 17 & 25 April 2016 & 5 & Pagi (08:00 wita) & 210 & TMS \\
\hline 18 & 25 April 2016 & 6 & Pagi (08:00 wita) & 28 & TMS \\
\hline 19 & 25 April 2016 & 1 & Siang (14:00 wita) & $>1100$ & TMS \\
\hline 20 & 25 April 2016 & 2 & Siang (14:00 wita) & 36 & TMS \\
\hline 21 & 25 April 2016 & 3 & Siang (14:00 wita) & 20 & TMS \\
\hline 22 & 25 April 2016 & 4 & Siang (14:00 wita) & 93 & TMS \\
\hline 23 & 25 April 2016 & 5 & Siang (14:00 wita) & $>1100$ & TMS \\
\hline 24 & 25 April 2016 & 6 & Siang (14:00 wita) & $>1100$ & TMS \\
\hline
\end{tabular}

Keterangan :

MS : Memenuhi Standar

TMS : Tidak Memenuhi Standar

Pada Tabel 2 terdapat tujuh sampel yang menunjukan pertumbuhan bakteri berwarna hijau metalik. Tujuh sampel tersebut adalah sampel yang berasal dari pedagang 1 pada pengenceran $10^{-2}$ yang diambil pada siang hari pada tanggal 7 April, sampel yang berasal dari pedagang 2 pada pengenceran $10^{-2}$ dan 10 ${ }^{-3}$ yang diambil pada siang hari pada tanggal 7 April, sampel yang berasal dari pedagang 3 pada pengenceran $10^{-3}$ yang diambil pada siang hari pada tanggal 7 April, sampel yang berasal dari pedagang 2 pada pengenceran $10^{-2}$ yang diambil pada pagi hari pada tanggal 25 April, sampel yang berasal dari pedagang 5 pada pengenceran $10^{-3}$ yang diambil pada pagi hari pada tanggal 25 April, sampel yang berasal dari pedagang 1 pada pengenceran $10^{-3}$ yang diambil pada siang hari pada tanggal 25 April dan sampel yang berasal dari pedagang 3 pada pengenceran $10^{-3}$ yang diambil pada siang hari pada tanggal 25 April. Untuk memastikan ketujuh sampel tersebut adalah Escherichia coli maka ke tujuh sampel tersebut diuji menggunakan uji biokimia indole, methyl red, voges proskauer dan citrate (IMViC). Setelah dilakukan uji biokimia diperoleh hasil seperti pada Tabel 3. 
Tabel 2.

Hasil Isolasi Terhadap 24 Sampel Nasi Campur di Lingkungan Pasar Badung.

\begin{tabular}{|c|c|c|c|c|c|c|}
\hline \multirow{2}{*}{ No } & \multirow{2}{*}{ Tanggal } & \multirow{2}{*}{ Pedagang } & \multirow{2}{*}{ Waktu pengambilan } & \multicolumn{3}{|c|}{ Hasil isolasi pada media EMBA } \\
\hline & & & & $10^{-1}$ & $10^{-2}$ & $10^{-3}$ \\
\hline 1 & 7 April 2016 & 1 & Pagi (08:00 wita) & 0 & 0 & 0 \\
\hline 2 & 7 April 2016 & 2 & Pagi (08:00 wita) & 0 & 0 & 0 \\
\hline 3 & 7 April 2016 & 3 & Pagi (08:00 wita) & 0 & 0 & 0 \\
\hline 4 & 7 April 2016 & 4 & Pagi (08:00 wita) & 0 & 0 & 0 \\
\hline 5 & 7 April 2016 & 5 & Pagi (08:00 wita) & 0 & 0 & 0 \\
\hline 6 & 7 April 2016 & 6 & Pagi (08:00 wita) & 0 & 0 & 0 \\
\hline 7 & 7 April 2016 & 1 & Siang (14:00 wita) & 0 & 1 & 0 \\
\hline 8 & 7 April 2016 & 2 & Siang (14:00 wita) & 0 & 1 & 1 \\
\hline 9 & 7 April 2016 & 3 & Siang (14:00 wita) & 0 & 0 & 1 \\
\hline 10 & 7 April 2016 & 4 & Siang (14:00 wita) & 0 & 0 & 0 \\
\hline 11 & 7 April 2016 & 5 & Siang (14:00 wita) & 0 & 0 & 0 \\
\hline 12 & 7 April 2016 & 6 & Siang (14:00 wita) & 0 & 0 & 0 \\
\hline 13 & 25 April 2016 & 1 & Pagi (08:00 wita) & 0 & 0 & 0 \\
\hline 14 & 25 April 2016 & 2 & Pagi (08:00 wita) & 0 & 1 & 0 \\
\hline 15 & 25 April 2016 & 3 & Pagi (08:00 wita) & 0 & 0 & 0 \\
\hline 16 & 25 April 2016 & 4 & Pagi (08:00 wita) & 0 & 0 & 0 \\
\hline 17 & 25 April 2016 & 5 & Pagi (08:00 wita) & 0 & 0 & 1 \\
\hline 18 & 25 April 2016 & 6 & Pagi (08:00 wita) & 0 & 0 & 0 \\
\hline 19 & 25 April 2016 & 1 & Siang (14:00 wita) & 0 & 0 & 1 \\
\hline 20 & 25 April 2016 & 2 & Siang (14:00 wita) & 0 & 0 & 0 \\
\hline 21 & 25 April 2016 & 3 & Siang (14:00 wita) & 0 & 0 & 1 \\
\hline 22 & 25 April 2016 & 4 & Siang (14:00 wita) & 0 & 0 & 0 \\
\hline 23 & 25 April 2016 & 5 & Siang (14:00 wita) & 0 & 0 & 0 \\
\hline 24 & 25 April 2016 & 6 & Siang (14:00 wita) & 0 & 0 & 0 \\
\hline
\end{tabular}

Menurut Standar Nasional Indonesia (SNI) 2897 : 2008 hasil Uji indole, Methyl Red, Voges Proskauer dan citrate (IMViC) terhadap Escherichia coli adalah + + - -. Oleh karena itu hasil uji biokimia terhadap ke tujuh sampel makanan yang berwarna hijau metalik pada media EMBA menunjukan hasil yang negatif terhadap bakteri E.coli. Hasil uji tersebut juga menandakan bahwa tidak ditemukan adanya kontaminasi bakteri E.coli pada makanan nasi campur yang dijual di Pasar Badung.

Dari hasil penelitian yang dilakukan oleh Bontong (2012) enam sampel daging se'i babi yang dipasarkan di enam tempat pembuatan daging se' $i$ di kota Kupang tercemar bakteri Escherichia coli dengan beban cemaran yang diperoleh melebihi batas maksimum cemaran bakteri Escherichia coli pada daging asap. Dari hasil penelitian yang dilakukan oleh Djaja (2008) didapatkan kontaminasi bahan makanan oleh bakteri coli tinja dan E.coli cukup tinggi yaitu masing-masing $83,5 \%$ dan $40 \%$ dengan jumlah bakteri coli tinja sekitar 2,7 x $10^{7} \mathrm{MPN} /$ gram sampel dan jumlah bakteri E.coli sekitar 1,6 x $10^{7}$ MPN/gram sampel. Yunita dan Dwipayanti (2010) juga menemukan bahwa sebanyak 47.8 \% makanan nasi jinggo yang dijual disekitar wilayah Denpasar Selatan terkontaminasi E.coli.

Escherichia coli adalah salah satu golongan bakteri coliform yang memiliki sifat dapat tumbuh pada suhu $10-40^{\circ} \mathrm{C}$, dengan suhu yang optimal yaitu $37^{\circ} \mathrm{C}$. E. coli relatif sangat sensitif terhadap panas dan dapat diinaktifkan pada suhu pasteurisasi makanan atau selama pemasakan makanan (Yunaenah, 2009). Bakteri E.coli merupakan bakteri gram negatif. Menurut Todar (2008) bakteri gram negatif tidak tahan 
terhadap perlakuan fisik artinya bakteri tersebut akan mati pada suhu $60^{\circ} \mathrm{C}$ selama 30 menit. Oleh karena itu tidak ditemukannya kontaminasi E.coli pada makanan nasi campur yang dijual di sekitar Pasar Badung diduga karena makanan tersebut telah mengalami proses pemanasan.

Tabel 3.

Hasil Uji Biokimia Terhadap Tujuh Sampel Positif Pada Media EMBA

\begin{tabular}{|c|c|c|c|c|c|c|c|c|}
\hline \multirow{2}{*}{ No } & \multirow{2}{*}{ Tanggal } & \multirow{2}{*}{ Pedagang } & \multirow{2}{*}{$\begin{array}{c}\text { Waktu } \\
\text { pengambilan }\end{array}$} & \multirow{2}{*}{ Pengenceran } & \multicolumn{4}{|c|}{ Hasil } \\
\hline & & & & & I & MR & VP & $\mathrm{C}$ \\
\hline 1 & 7 April 2016 & 1 & Siang & $10^{-2}$ & + & + & - & + \\
\hline \multirow[t]{2}{*}{2} & 7 April 2016 & 2 & Siang & $10^{-2}$ & - & + & - & + \\
\hline & 7 April 2016 & 2 & Siang & $10^{-3}$ & - & + & - & + \\
\hline 3 & 7 April 2016 & 3 & Siang & $10^{-3}$ & - & + & - & + \\
\hline 4 & 25 April 2016 & 2 & Pagi & $10^{-2}$ & + & + & - & + \\
\hline 5 & 25 April 2016 & 5 & Pagi & $10^{-3}$ & - & + & - & + \\
\hline 6 & 25 April 2016 & 1 & Siang & $10^{-3}$ & + & + & - & + \\
\hline 7 & 25 April 2016 & 3 & Siang & $10^{-3}$ & - & + & - & + \\
\hline \multicolumn{9}{|c|}{ Keterangan : } \\
\hline I & Indole & & & & & & & \\
\hline $\mathrm{MR}$ & Methyl Red & & & & & & & \\
\hline VP & Voges Proskauer & & & & & & & \\
\hline $\mathrm{C}$ & Citrate & & & & & & & \\
\hline
\end{tabular}

Tidak ditemukannya E.coli juga dapat disebabkan karena bakteri E.coli mempunyai daya tahan lebih rendah jika dibandingkan bakteri coliform jenis lain (BPOM, 2003). Telah disebutkan diatas bahwa bakteri E.coli mempunyai daya tahan yang lebih rendah dibandingkan coliform jenis lain sehingga dapat dimungkinkan keberadaan E.coli di sekitar pedagang nasi campur lebih sedikit (Primaningrum, 2006). Hasil penelitian Murtiningtyas (2016) terhadap bakteri Escherichia coli pada minuman susu kedelai, terdapat 5 sampel yang terindentifikasi coliform tetapi bukan dari jenis bakteri E.coli. Hal ini di sebabkan karena penaganan yang tepat.

Meskipun semua sampel yang diuji tidak terkontaminasi E.coli namun makanan nasi campur yang dijual di sekitar pasar melebihi syarat jumlah coliform yang telah ditentukan. Berdasarkan hasil uji peneguhan diperoleh bahwa semua sampel yang diuji (100\%) tidak memenuhi syarat Most Probable Number (MPN) coliform yang telah ditetapkan sesuai dengan Standar Nasional Indonesia (SNI) 2897 : 2008 yaitu <3.6 MPN/gr. Menurut Djaja (2008) makanan yang disajikan oleh pedagang kaki lima tidak layak santap karena masih mengandung coliform $67,1 \%$, coli tinja $44.7 \%$ dan E.coli $18.8 \%$. Hal ini sejalan dengan penelitian yang dilaporkan oleh Sukmara (2008) bahwa kontaminasi coliform makanan saji di tempat pengelolaan makanan sebesar $45.1 \%$. Penelitian yang dilakukan oleh Primaningrum (2006) menemukan bahwa $100 \%$ dari 13 sampel sate ikan languan tidak memenuhi persyaratan kandungan coliform.

Coliform merupakan suatu grup bakteri yang terkandung dalam jumlah banyak pada kotoran manusia dan hewan sehingga bakteri ini sering dipakai sebagai indikator dari kualitas makanan, air dan adanya kontaminasi kotoran (Entjang, 2010). Menurut Yunita dan Dwipayanti (2010) tingginya kontaminasi coliform dapat disebabkan oleh sanitasi yang masih sangat rendah dan lingkungan yang buruk, adanya kontak langsung tangan pedagang dengan bahan makanan, personal hygiene, pengelolahan makanan yang tidak tepat dan keberadaan vector pembawa mikroorganisme. 


\subsection{Total Plate Count (TPC)}

Total Plate Count (TPC) adalah seluruh koloni yang tumbuh pada bahan pangan ataupun produk jadi (BPOM, 2003). Sampel yang digunakan sama seperti sampel yang digunakan pada analisa kontaminan bakteri Escherichia coli yaitu nasi campur. Hasil pengujian terhadap 24 sampel yang digunakan ditampilkan pada Tabel 4.

Menurut surat keputusan Dirjen POM Nomor : 03726/B/SK/VII/89, batas Total Plate Count (TPC) pada makanan adalah $1 \times 10^{6} \mathrm{CFU} / \mathrm{g}$. Berdasarkan Tabel 4 dapat dilihat bahwa dari 24 sampel yang diuji terdapat 22 sampel (91.7\%) tidak memenuhi standar batas minimal cemaran bakteri yang telah ditentukan dan hanya dua sampel (8.3\%) yang memenuhi standar yaitu sampel yang di ambil pada siang hari dari pedagang tiga pada tanggal 25 April 2016. Pada penelitian yang dilakukan oleh Suryadarma (2007) ditemukan 37.2\% sampel yang tidak memenuhi syarat parameter TPC dari 231 sampel makanan yang diperiksa. Makanan tersebut yaitu: minuman ringan dan sari buah, mie kering, air minum dalam kemasan, daging asap yang diolah dengan panas, sosis, bakso, es lilin, kripik ayam, serta tepung dan hasil olahannya.

Berdasarkan hasil uji analisis kontaminan bakteri Eschericia coli dan Total Plate Count (TPC) yang telah dilakukan menunjukkan bahwa makanan yang dijual disekitar pasar Badung tidak layak untuk dikonsumsi. Hal itu disebabkan karena adanya jumlah coliform dan cemaran bakteri yang melampaui syarat yang telah ditentukan. Menurut Sanjaya dan Apriliani (2013) terdapat berbagai faktor yang mempengaruhi terjadinya kontaminasi bakteri pada makanan. Oleh karena itu peneliti melakukan observasi untuk mengetahui faktor-faktor yang menyebabkan terjadinya kontaminasi pada makanan yang dijual di sekitar pasar Badung. Objek pengamatan observasi meliputi :

1) Lokasi dan sarana penjualan merupakan salah satu faktor pendukung terjadinya kontaminasi. Hasil observasi menunjukkan bahwa semua pedagang berada pada arah angin dari sumber pencemaran seperti asap kendaraan, debu, bau dan cemaran lainnya serta berada kurang dari 100 meter terhadap sumber pencemaran. Mikroba dapat mencemari pangan melalui air, debu, udara, tanah, alat-alat pengolah (selama proses produksi atau penyiapan) juga sekresi dari usus manusia atau hewan (BPOM, 2008). Kontaminasi juga dapat disebabkan oleh kondisi gerobak atau tempat jualan yang kotor dan tidak dibersihkan setelah digunakan sehingga dapat mengakibatkan tingginya pertumbuhan agen mikrobiologis.

2) Fasilitas sanitasi juga merupakan hal yang harus diperhatikan dalam pengolahan dan penyajian makanan. Fasilitas sanitasi yang memadai dapat diukur dari tersedianya air bersih, adanya pembuangan air limbah, tempat sampah, tempat mencuci tangan, bahan makanan dan peralatan, serta ruangan makan bagi konsumen. Hasil observasi menunjukkan bahwa tidak tersedia air bersih yang cukup untuk mencuci tangan, bahan makanan dan peralatan. Air yang digunakan juga bukan merupakan air dari PDAM tetapi berasal dari air sumur dan digunakan berulang kali. Hal tersebut merupakan faktor penyebab tingginya kontaminasi mikroba. Pada penelitian terhadap es dawet di Ponorogo terdapat hubungan antara kualitas air bersih dengan kandungan E.coli (Deni, 2012). Menurut Sukmara (2008) kontaminasi tangan pengolah makanan yang kotor dapat memindahkan bakteri dan mengontaminasi makanan, terutama bakteri patogen makanan sebesar $83.9 \%$.

3) Pemilihan bahan baku menjadi salah satu perhatian utama pada pengolahan makanan. Bahan baku yang baik akan menghasilkan produk yang baik pula asal diolah dengan cara yang tepat. Suryadarma (2007) menyebutkan bahwa bahan baku yang busuk, tidak segar dan utuh kemungkinan sudah men- 
galami kontaminasi serta pembusukan dan tidak layak dimakan. Menurut Departemen Kesehatan (2004) untuk mendapatkan bahan makanan yang baik perlu diketahui sumber-sumber makanan yang baik. Hasil observasi menunjukkan bahwa semua bahan baku yang diolah dalam keadaan baik dan berasal dari sumber resmi sehingga dapat dikatakan bahwa kontaminasi yang terjadi pada makanan nasi campur di sekitar pasar Badung bukan berasal dari bahan baku yang digunakan.

4) Tahap penting lainnya adalah penyajian makanan, karena pada tahap ini mikroorganisme dapat berkembang biak dan dapat terjadi kontaminasi pada makanan. Pada praktiknya, pedagang nasi campur di lingkungan Pasar Badung Bali kurang memahami cara penyajian yang baik. Hal itu dapat dilihat dari kebiasaan pedagang tersebut yang menyajikan makanan kepada pembeli dalam keadaan dingin menggunakan pewadahan yang kotor dan penjamahan makanan tidak menggunakan peralatan yang bersih (menggunakan tangan). Hal ini dapat meningkatkan terjadinya kontaminasi oleh agen mikrobiologi.

Tabel 4.

Kualitas Mikroorganisme Nasi Campur Berdasarkan Total Plate Count (TPC)

\begin{tabular}{|c|c|c|c|c|c|}
\hline No & Tanggal & Pedagang & Waktu pengambilan & Nilai TPC (CFU/g) & Keterangan \\
\hline 1 & 7 April 2016 & 1 & Pagi (08:00 wita) & $1.8 \times 10^{6}$ & TMS \\
\hline 2 & 7 April 2016 & 2 & Pagi (08:00 wita) & $1.5 \times 10^{6}$ & TMS \\
\hline 3 & 7 April 2016 & 3 & Pagi (08:00 wita) & $2.6 \times 10^{5}$ & MS \\
\hline 4 & 7 April 2016 & 4 & Pagi (08:00 wita) & $2.6 \times 10^{6}$ & TMS \\
\hline 5 & 7 April 2016 & 5 & Pagi (08:00 wita) & $6.5 \times 10^{7}$ & TMS \\
\hline 6 & 7 April 2016 & 6 & Pagi (08:00 wita) & $2.2 \times 10^{6}$ & TMS \\
\hline 7 & 7 April 2016 & 1 & Siang (14:00 wita) & $1.5 \times 10^{8}$ & TMS \\
\hline 8 & 7 April 2016 & 2 & Siang (14:00 wita) & $2.1 \times 10^{6}$ & TMS \\
\hline 9 & 7 April 2016 & 3 & Siang (14:00 wita) & $1.9 \times 10^{6}$ & TMS \\
\hline 10 & 7 April 2016 & 4 & Siang (14:00 wita) & $8.9 \times 10^{6}$ & TMS \\
\hline 11 & 7 April 2016 & 5 & Siang (14:00 wita) & $1.6 \times 10^{8}$ & TMS \\
\hline 12 & 7 April 2016 & 6 & Siang (14:00 wita) & $2.4 \times 10^{6}$ & TMS \\
\hline 13 & 25 April 2016 & 1 & Pagi (08:00 wita) & $1.7 \times 10^{6}$ & TMS \\
\hline 14 & 25 April 2016 & 2 & Pagi (08:00 wita) & $1.5 \times 10^{6}$ & TMS \\
\hline 15 & 25 April 2016 & 3 & Pagi (08:00 wita) & $4.9 \times 10^{5}$ & MS \\
\hline 16 & 25 April 2016 & 4 & Pagi (08:00 wita) & $2.2 \times 10^{6}$ & TMS \\
\hline 17 & 25 April 2016 & 5 & Pagi (08:00 wita) & $5.3 \times 10^{7}$ & TMS \\
\hline 18 & 25 April 2016 & 6 & Pagi (08:00 wita) & $2.0 \times 10^{6}$ & TMS \\
\hline 19 & 25 April 2016 & 1 & Siang (14:00 wita) & $1.2 \times 10^{8}$ & TMS \\
\hline 20 & 25 April 2016 & 2 & Siang (14:00 wita) & $1.9 \times 10^{6}$ & TMS \\
\hline 21 & 25 April 2016 & 3 & Siang (14:00 wita) & $1.8 \times 10^{6}$ & TMS \\
\hline 22 & 25 April 2016 & 4 & Siang (14:00 wita) & $7.0 \times 10^{6}$ & TMS \\
\hline 23 & 25 April 2016 & 5 & Siang (14:00 wita) & $1.2 \times 10^{8}$ & TMS \\
\hline 24 & 25 April 2016 & 6 & Siang (14:00 wita) & $2.7 \times 10^{6}$ & TMS \\
\hline
\end{tabular}

Keterangan :

MS : Memenuhi Syarat

TMS : Tidak Memenuhi Syarat

5) Peralatan dan sarana penjualan juga memegang peranan penting untuk mencegah terjadinya kontaminasi pada makanan. Dari hasil pengamatan yang dilakukan ditemukan masih banyak pedagang di sekitar Pasar Badung yang tidak memperhatikan cara pencucian, pengeringan dan penyimpanan peralatan agar selalu dalam keadaan bersih sebelum digunakan serta perlatan yang digunakan tidak 
semuanya dalam keadaan baik. Menurut Riyanto dan Abdillah (2012) peralatan dan sarana penjualan harus memenuhi persyaratan hygiene dan sanitasi untuk mencegah terjadinya kontaminasi oleh agen mikrobiologis.

6) Hygiene dan sanitasi pedagang juga merupakan hal yang harus diperhatikan dalam mengolah dan menyajikan makanan. Berdasarkan hasil observasi yang dilakukan masih banyak pedagang yang mencuci tangan menggunakan air yang tidak mengalir. Disamping itu juga ditemukan bahwa berbagai peralatan dan air yang digunakan jarang diganti. Penjamah makanan juga tidak mengikuti persyaratan sesuai Keputusan Menteri Kesehatan Republik Indonesia Nomor 942/Menkes/SK/2003 yaitu menggunakan pakaian bersih, tutup mulut saat bersin, tidak mengunyah makanan saat mengolah makanan, menjaga kebersihan kuku dan tidak menggunakan perhiasan. Menurut Taylor et al., (2009) terdapat bukti dari industri makanan yang menunjukkan bahwa mikroorganisme ditransfer dalam proses penanganan makanan melalui kurangnya kebersihan perorangan sehingga tangan terkontaminasi oleh patogen. Oleh karena itu kebersihan perorangan (personal hygiene) sangat penting bagi pengolah makan.

\section{Kesimpulan}

Dari hasil penelitian ini dapat disimpulkan bahwa tidak terdapat kontaminan Bakteri Escherichia coli pada makanan nasi campur yang di jual di lingkungan Pasar Badung Bali. Dilihat dari hasil Total Plate Count (TPC) atau Angka Lempeng Total bakteri 91.7\% makanan nasi campur di sekitar Pasar Badung tidak sesuai standar dan hanya $8.3 \%$ makanan nasi campur yang memenuhi standar yang telah ditetapkan oleh Dirjen POM Nomor : 03726/B/SK/VII/89.

\section{Referensi}

Badan Pengawasan Obat dan Makanan. (2003). Mutu Pangan. Direktorat Surveilan dan Penyuluhan Keamanan Pangan Deputi III - BPOM. Jakarta.

Badan Pengawas Obat dan Makanan (2003). Higiene dan Sanitasi Pengolahan Pangan. Direktorat Surveilans dan Penyuluhan Keamanan Pangan Deputi Bidang Pengawasan Keamanan Pangan dan Bahan Berbahaya. Jakarta.

Badan Pengawas Obat dan Makanan Republik Indonesia (2008). Info POM. Pengujian Mikrobiologi Pangan. 9 (2). Maret 2008.

Bontong, A.R., Mahatmi, H., \& Suada, I. K. (2012). Kontaminasi Bakteri Escherichia coli Pada Daging Se'i Yang Dipasarkan Di Kota Kupang. Fakultas Kedokteran Hewan Universitas Udayana. Denpasar.

Deni, I. (2012). Uji Bakteri Escherichia Coli Pada Minuman Susu Kedelai Bermerek Dan Tanpa Merek Di Kota Surakarta. Skripsi. Fakultas Kedokteran. Jurusan Pendidikan Dokter. Universitas Muhammadiyah Surakarta.

Departemen Kesehatan RI. (2010). Modul Kursus Hygiene dan Sanitasi Makanan dan Minuman. Departemen Kesehatan Republik Indonesia Ditjen PPM \& PLP. Jakarta.

Departemen Kesehatan RI. (2004). Hygiene Sanitasi Makanan dan Minuman. Jakarta: Dirjen PPM dan PL.

Djaja, M. (2008). Kontamiasi E.coli Pada Makanan dari Tiga Jenis Tempat Pengelolaan Makanan (TPM) di Jakarta Selatan, Jurnal Kesehatan, 12(1). Juni 2008.

Entjang, I. (2010). Mikrobiologi dan Parasitologi untuk Akademi Keperawatan dan Sekolah Tenaga Kesehatan yang Sederajat. PT. Citra Aditya Bakti, Bandung.

Murtiningtyas, S. (2016). Uji Bakteri Escherichia coli Pada Minuman Susu Kedelai dari Beberapa Penjual Susu Kedelai di Kota Surakarta. Naskah Publikasi. Fakultas Kedokteran Universitas Muhammadiyah Surakarta. Surakarta.

Primaningrum, A.A.A. W. (2006). Higiene Perorangan Penjamah Makanan dan ualitas Mikrobiologis Sate Ikan Languan yand dijual di pantai Lebih KAbupaten Gianyar. Program Studi Ilmu Kesehatan Universitas Udayana Denpasar. Skripsi

Riyanto, A., \& Abdillah, A. D. (2012). Faktor yang Memengaruhi Kandungan E. coli Makanan Jajanan SD di 
Wilayah Cimahi Selatan. MKB, 44,77-82

Sanjaya, T.A., \& Apriliana, T. (2013). Deteksi Escherichia coli pada jajanan cendol yang dijual di pasar tradisional Bandar lampung. ISSN. 2337,10-17.

Singapurwa, N.M.A.S., Semariyani, A.A.M., \& Candra, I.P. (2017). Identification of the Implementation of GMP and SSOP on the Processing of the Balinese Traditional Food Sardine Pedetan. International Research Journal of Engineering, IT and Scientific Research, 3(3),17 - 26.

Standar Nasional Indonesia (2008). Analisa Cemaran Bakteri Escherichia coli dan penghitungan Total Plate count. SNI $2897: 2008$.

Sukmara, R. (2008). Faktor Sanitasi yang Berhubungan Dengan Koliform Pada Makanan Matang di tempat Pengolahan Makanan Daerah Jakarta Selatan. Skripsi. Fakultas Kesehatan Masyarakat. Universitas Indonesia, Depok.

Suryadarma, A.E. (2007). Pemeriksaan Sampel Kosmetik Secara Mikrobiologis di Laboratorium Mikrobiologi Balai Besar Pengawasan Obat dan Makanan (POM) Denpasar. Jurusan Biologi Fakultas Matematika dan Ilmu Pengetahuan Alam Universitas Udayana, Denpasar.

Taylor, H., Brown, K., Toivenne, J., \& Holah, J. (2009). A Microbiological Evaluation of Warm Air Hand Driers with Respect to Hand Hygiene and The Washroom Environment. J. Appl. Microbiology, 89: 910-919.

Yunita, N.L.P \& Dwipayanti, N.M.U. (2010). Kualitas Mikrobiologi Nasi Jinggo Berdasarkan Angka Lempeng Total, Coliform Total dan Kandungan Escherichia coli. Fakultas Kedokteran Universitas Udayana. Denpasar. 